\title{
LA INVESTIGACIÓN ARTÍSTICA EN EL SISTEMA ARTE-CULTURA: hacia una Educación Artística Emancipadora
}

\author{
Christian Proaño
}

\section{Resumen:}

En este texto quiero plantear una alternativa de paradigma en la educación artística, de una basada en disciplinas hacia una enfocada en la investigación autorreflexiva en el campo del sistema artecultura aplicada a la producción material del arte desde prácticas individuales, de taller y "sociales", y que planteo, siguiendo a Ranciere, como emancipadora.

Palabras claves: educación en arte,educación emancipadora,sistema arte-cultura,investigación reflexiva

\begin{abstract}
:
This text stablishes an alternative paradigm to art education: From a paradigm based on disciplines, towards one focused on self-reflexive research. Quoting Rancière, this new paradigm is emancipating applied in the field of the art-culture system, to the individual material production in studio and social practices.
\end{abstract}

Keywords: art education, emancipatory education, art-culture system, self-reflexive research

\footnotetext{
Autor:

Christian Proaño (Quito, 1978). Artista audiovisual. Bachiller en Artes Plásticas, Licenciado en Sónicas y Magíster en Antropología Visual. Investiga el paisaje sonoro y el ruido en todas sus formas. Ha expuesto y tocado en distintas ciudades del Ecuador y Sudamérica. Cofundador de la rED rUIDISTAS, plataforma de intervención aleatoria en el paisaje sonoro. Coedita el fanzine de crítica cultural quiteña WiriWiri. www.chrispunksonico.blogspot.com
} 
"Maestro es el que mantiene al que busca en su rumbo, ese rumbo en el que cada uno está solo en su búsqueda y en el que no deja de buscar."

Ranciere

En el ámbito de la enseńanza artística en general y, sobre todo en las universidades, está latente la necesidad de dejar atrás el modelo de enseñanza disciplinario, modernizado en los ańos veinte por Bauhaus, basado en la Historia del Arte progresista y lineal, así como de la trasmisión de las técnicas de las Bellas Artes. Paradigma que a su vez naturaliza y profundiza las divisiones del mundo construidas en la Modernidad (ej. Arte/diseño) y que por tanto perpetúan diferencias, exclusiones y estereotipos usados para la dominación del Otro/s.

El apremio por una transformación en la enseñanza del arte no está desvinculado de esa búsqueda de cambio a nivel social, en general, donde este modelo estético juega un rol importante en la reproducción del sistema, pues el artista es concebido en medida de su funcionalidad para la industria y el mercado; el mejor ejemplo de ello son las industrias culturales que, mediante sus formas, prácticas y discursos clásico -occidentales, refuerzan el sistema dominante.

Centrando el debate en la educación de las artes visuales, muchas instituciones a todo nivel, pero sobre todo las universidades que forman artistas practicantes, docentes, a quienes combinan ambos quehaceres, se encuentran con esa necesidad de cambiar la educación en el arte. Yo mismo fui educado con un currículo muy Bauhaus en el Colegio Universitario de Artes de la Universidad Central de Quito a finales de los ańos noventa. La malla partía de bases de diseño y teoría del color hasta todas las técnicas de taller y estaba atravesada de la metodología del dibujo con modelo. A este currículo de enseñanza de las Artes Visuales no solamente es necesario añadir lo que se ha venido en llamar los Nuevos Medios, que podrían ser los que han logrado más inclusión, aunque bajo la misma perspectiva disciplinar; sino también habría que introducir las prácticas estéticas relacionales, comunitarias y colaborativas, la acción y el "performance", todas estas expresiones artísticas actuales en el campo de la visualidad que deben ser insertadas bajo una lógica distinta a la de las vanguardias ( líneal y progresista) tanto en el taller (expandido) como en el relato de la Historia del Arte. De la mano de estas medidas y sin lo cual el cambio emancipador no sería posible, resulta imprescindible poner bajo discusión las oposiciones construidas por la Modernidad en este régimen educativo, entre categorías como arte culto y arte popular, o entre arte moderno y arte contemporáneo, arte y artesanía, o finalmente inteligencia superior e inteligencia inferior ${ }^{1 .}$ Discutir estas dicotomías, esenciales de los relatos lineales modernos, nos permitiría situarnos en un campo de acción artística: investigación / experimentación / producción. Como describe el antropólogo James Clifford (1988), a lo que denomina el Sistema Arte Cultura, aplicado a las colecciones etnográficas, este concepto trasladado al campo del Arte permite pensarlo como un campo de acción : un sistema simbólico de producción y valoración de artefactos estéticos, y que de cierta forma integra al campo del Arte moderno, y a través de su negación, las movidas "duchampianas" de incluir la vida cotidiana y la reproducción mediática, todo lo que es valorado o no como Arte en función del juego de lenguaje en el que se inserten (Wittgenstein,1953).

Este salto antropológico tiene sus correlatos en el campo artístico y quisiera especialmente señalar a la

1 "El mito pedagógico () divide el mundo en dos. Pero es necesario decir más precisamente que divide la inteligencia en dos. Lo que dice es que existe una inteligencia inferior y una inteligencia superior. La primera registra al azar las percepciones, retiene, interpreta y repite empiricamente, en el estrecho círculo de las costumbres y de las necesidades. Esa es la inteligencia del niño pequeño y del hombre del pueblo. La segunda conoce las cosas a través de la razón, procede por método, de lo simple a lo complejo, de la parte al todo. Es ella la que permite al maestro transmitir sus conocimientos adaptándolos a las capacidades intelectuales del alumno y la que permite comprobar que el alumno ha comprendido bien lo que ha aprendido. (Esta clasificación de inteligencias) es el principio de la explicación. Tal será en adelante para Jocotot el principio del atontamiento"(Ranciere:9) 


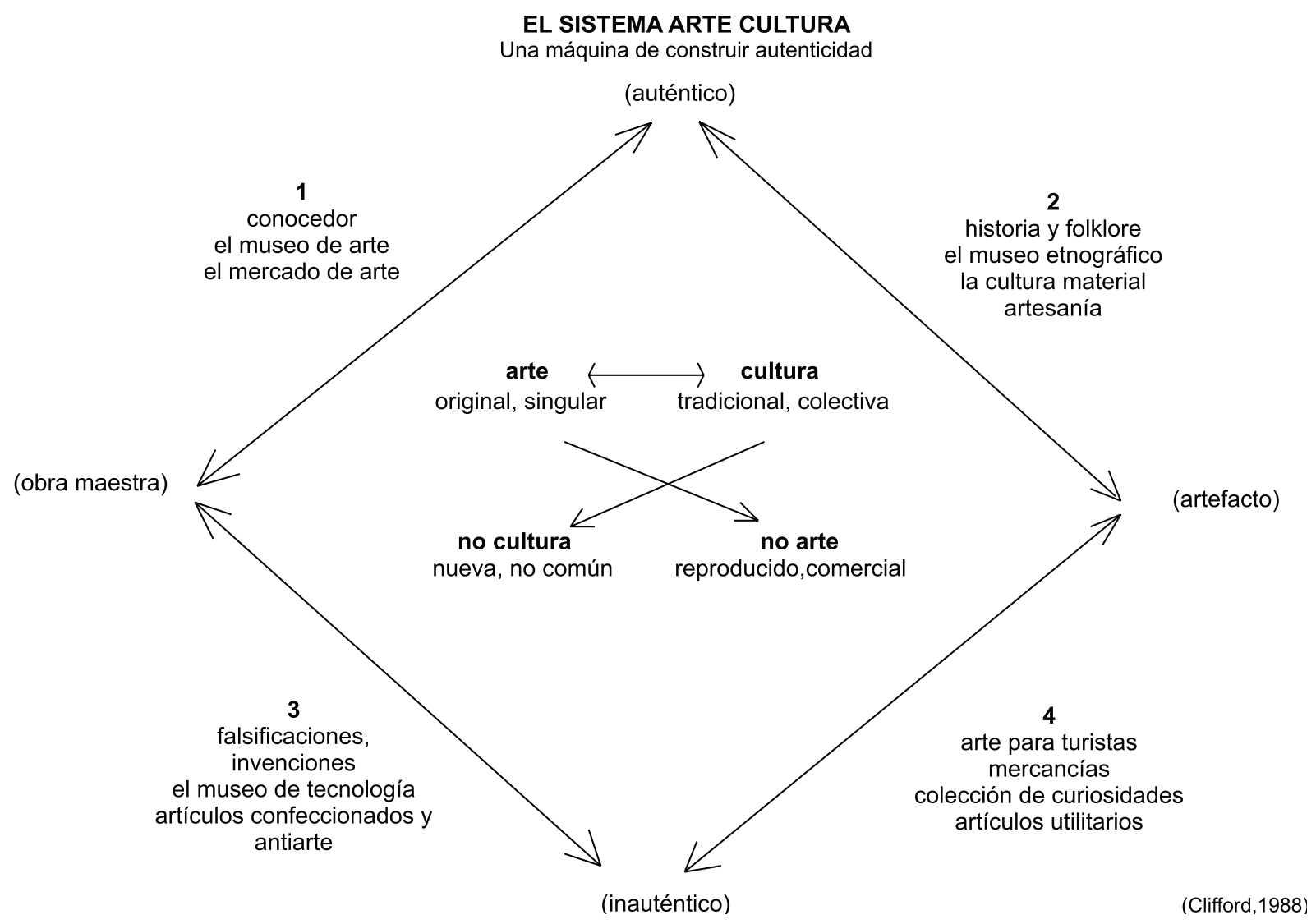

división del sistema-mundo artístico en 4 campos. el Arte, el anti-arte, el no-arte y el des-arte realizada por Allan Kaprow por lo menos 20 años antes que Clifford, que aunque sin incluir cabalmente el concepto de cultura, como lo hace el antropólogo, sí incluye la idea de vida cotidiana. Los cuatro campos semánticos descritos abajo para el caso de las colecciones etnográficas pueden ayudarnos a reflexionar más ampliamente sobre el arte y la cultura en general, como un espejo reflejando lo propuesto por Kaprow:

campo 1 es el campo de la alta cultura o de el Artearte

campo 2 es el campo del folclore, la artesanía o del no arte

campo 3 es el campo de las falsificaciones o del antiarte

campo 4 es el campo de la cultura mediática, masiva, popular o del des-arte,

y así intentar delimitar un posible campo, un lugar, un espacio y un tiempo para la investigaciónexperimentación artística en el cual se desenvolvería la clase de arte, el taller expandido, el laboratorio. Este sistema incluye todas las manifestaciones estéticas de una sociedad y no solamente las consideradas Bellas Artes o alta cultura, todas en situación de igualdad e importancia y cada cual con su genealogía, varias, emparentadas entre sí.

En actuales debates de la pedagogía artística contemporánea, existe amplio consenso en que, como dice Aguirre (2004), enseñar arte es instruir también sobre los contextos culturales en que se producen los objetos, hechos, experiencias artísticas y la manera en que son valoradas, sentidas por la sociedad. De esta manera, la educación en el arte no estaría limitada a adiestrar en los conocimientos formales para reproducir técnicamente un artefacto estético, 
sino que forjaría y fortalecería la comprensión de la performatividad ${ }^{2}$ de los artefactos artísticos, la cual "reside en que las obras se usan y "reproducen" en cada contexto en el que son consideradas como tales. Los artefactos artísticos se usan y reproducen, independientemente del conocimiento que tenga el receptor-intérprete del sistema de reglas con las que fueron producidos e, incluso, del origen cultural de los mismos. Para que cualquier producto artístico genere significación estética, solo debemos disponer, por tanto, de contextos o espacios simbólicos adecuados, dispuestos a reconocer las características sistémicas de tal constructo estético como arte" (Ib). Esta es la capacidad y poder del arte, construir un contexto simbólico, para determinar hechos o experiencias como estéticas o no, como arte o no.

Este cambio de paradigma en la enseñanza artística, de uno de tipo disciplinar y lineal, a otro, transdisciplinar y complejo, tendría dos consecuencias importantes: la primera, que señalaba ya Geertz, el preguntarnos qué es lo que se puede decir del arte al interpretarlo dentro de sistemas simbólicos, Esta pregunta, frecuente a partir de los ochenta, sobre todo desde la antropología, ha ocasionado molestia y rechazo por parte de gran parte de artistas al sentir su voz usurpada, sus obras interpretadas como signos abstractos, sin contexto insertadas en todo tipo de redes de significados. Además, esta interrogante, usada como herramienta reflexiva tanto en la enseñanza como en la investigación artísticas, permite que el artista sea autocrítico con su propio trabajo y sea capaz, a la vez, de observar la forma en que su propia autocritica fue construida, es decir de producir reflexivamente: ¿qué es lo que puedo decir sobre mi trabajo3? La segunda consecuencia, permite al artista, estudiante de arte, investigador, situarse e insertar su trabajo en redes de significados, en los que su obra pueda tener un valor o una relevancia, sea en la galería, en la calle, etc. Mostrar no solamente que los contextos se construyen socialmente sino que el artista puede

2 Es el propio Aguirre el que usa la palabra performatividad.

3 "sobre lo que no podemos hablar debemos guardar silencio" (Wittgenstein,1921) tener agencia en su construcción. ¿Por qué es esto importante? Pues, porque la investigación artística se puede llevar a cabo desde cualquier contexto de redes de significados, pero es necesario esclarecer las redes para poder situarnos en el campo de estudio. Aguirre ejemplifica con el enseñar a reproducir una máscara Yorubá - bien podría ser un paisaje o una acción- las redes de significados en que puede estar situada, o las redes de significados convencionales que hacen un paisaje. Las genealogías construidas socialmente, a lo largo de la historia, en distintas culturas, son un constructo estético cultural que fácilmente puede ser trasladado a otros contextos culturales, reproduciendo así, no las formas de un paisaje o una máscara sino, sus usos en la red de significados llamado arte-cultura. En este orden de cosas es que se hace relevante la investigaciónexperimentación artística, entendida, en términos de la capacidad o de la sensibilidad de insertar un hecho o una experiencia estéticas en una red de significados artísticos, algo que se puede hacer tanto en el taller como fuera de él.

Aquí quiero detenerme para describir algunos aportes, sobre todo metodológicos, desde la Antropología como disciplina, a la investigación-experimentación artística, no solamente en un posible "campo" de la cultura, como sería la primera posibilidad, y más obvia, sino sobre todo en la propia práctica artística tanto individual como colectiva.

La gran categorización de la Antropología como una disciplina radica, entre otras cosas, por su método de investigación: la observación participante, la cual requiere producción reflexiva, de quienes se dedican a una investigación en este ámbito. Este tipo de producción bien podría ser tomado desde las prácticas artísticas, en los talleres, en el "campo", mediante trabajo comunitario, pedagógico, relacional o colaborativo. Igual de importante, para una investigación en el arte, resulta observarse haciendo, mientras, al mismo tiempo nos preguntamos, ¿cómo es que hacemos en la forma en que hacemos?, expresando estas dos reflexiones en lo que estamos haciendo e involucrando de ese proceso también a la 
audiencia, como lo explica Rosanna Hertz (Hertz en Wynne 2010) :

"Al juntar sujeto y objeto en el mismo espacio (a veces incluso la misma oración), los autores dan a sus audiencias la oportunidad de evaluarlas como "actores situados" (participantes activos en el proceso de creación de sentido)".

La emergencia de esta reflexividad se apoya en la aplicación de un método de observación participante, inclusive de autoobservación, en la cual el o la artista, como participante del proceso atiende con conciencia su hacer en relación consigo mismo y el mundo, dialoga, interpreta. Justamente, otra de las fortalezas metodológicas de la antropología es enfatizar como conocimiento reflexivo participante, el diálogo, generador de conocimiento, en el caso del arte, generador de hechos y experiencias estéticas. El diálogo entendido en términos de escucha "con simpatía" (Muratorio,2005) con uno mismo, con la Historia del Arte, con la sociedad y sus redes de significación y de poder, de los que uno mismo forma parte.

Sin embargo, yo había empezado este ensayo con una promesa: educación emancipadora y hasta ahora solo he delimitado una propuesta de campo y de mirada. Para poder discutir la idea de educación emancipadora voy a seguir a Jaques Ranciere y su texto El Maestro Ignorante; no obstante, también tengo presente mi experiencia en el aula, laboratorio, y taller en distintos contextos de educación/ aprendizaje tanto institucional como informal, no planteándola ejemplar, más bien para transparentar la metodología que apliqué: la observación participante para un diálogo reflexivo.

Para que la educación sea emancipadora, siguiendo a Ranciere, tiene que obligar al estudiante a utilizar su inteligencia en libertad; esta pedagogía se basa en la investigación empírica, en la experiencia (experimentación y expresión) para "dar (al estudiante) la conciencia de lo que puede una inteligencia cuando se considera igual a cualquier otra y considera cualquier otra como igual a la suya"
(Ranciere, 25). La enseñanza del arte tiene lugar, como propongo en párrafos previos, en el sistema arte-cultura, o en cualquiera de esos intersticios, que no necesariamente significa un lugar físico, pero que obviamente incluye al taller o la cabeza del artista; y la observación participante como mirada autorreflexiva, dialogante, subjetiva.

La reflexión que estructura este ensayo está permeada por la lectura sobre las experiencias pedagógicas, sobre todo de Roy Ascott, en sus foundations, en las universidades británicas en las que empezó a experimentar desde los años 60. Me interesa en Ascott sobre todo su definición del campo de investigación artística como uno transdiciplinar de Realidad Variable. A esta realidad variable de Ascott yo le atravieso las nociones del sistema arte-cultura de Geertz. El sistema existe en la realidad variable por lo que una obra de arte puede existir tanto en la realidad verificable como en la virtual o en la vegetal, y lo mismo con una falsificación, con una artesanía o con un artefacto de la cultura popular, que existen en muchas formas de la realidad y en los tránsitos entre esas realidades. Pienso aquí por ejemplo en los barros Shuar o Huao que existieron siempre primero en una realidad vegetal y luego mediante visiones -producidas al consumir brebajes preparados a partir de plantas sagradas- son representadas, moldeadas fomando artefactos en barro cocido con usos funcionales en la realidad verificable y que después son apropiados por el mercado de "souvenirs" de lugares y tiempos distantes.

Por "clase de arte", aquí me refiero, a aquella materia impartida en escuelas y colegios llamada Educación Estética, y a nivel universitario, a la clase de investigación artística, laboratorios o talleres de investigación, talleres de tesis, talleres trans o interdisciplinarios, enfocados en la investigación y experimentación que el profesor de arte no dirigirá, ni desempeñará el papel del maestro que conoce todo el compendio de una técnica, tampoco mandará a investigar al estudiante las cosas que él ya sabe, para poder comprobar. "El maestro ignorante hará menos y más a la vez, no verificará lo que ha encontrado 
el alumno, comprobará que lo ha buscado"(Ibid:21) que deberá ser siempre algo material, un objeto, un libro, una cita, una nota, una imagen, un recuerdo, un deseo.

"Una cosa material es, en primer lugar, "el único puente de comunicación entre dos espiritus"' (Ibid) ${ }^{4}$. "El puente es paso, pero también distancia mantenida. La materialidad del libro pone a dos espíritus a una distancia que los mantiene como iguales, mientras que la explicación es aniquilación de uno por el otro. Pero la cosa es una instancia siempre disponible para comprobación material"(Ibid). Por eso no abogo de ninguna manera por profesores de artes formados en todas las posibles disciplinas, inter y transcontenidas en el sistema arte-cultura, ni en docentes etnógrafos, más bien apuesto por el maestro ignorante que propone Ranciere, porque "se puede enseñar lo que se ignora si se emancipa al alumno, es decir, si se le obliga a usar su propia inteligencia" (Ibid). Sin embargo, preguntémonos qué es lo que el profesor de arte debe ignorar. Yo propongo que lo que debemos ignorar como docentes, no saber de antemano, es la búsqueda personal de cada estudiante. El profesor de arte debe ser una guía de técnicas y saberes, pero sobre todo de búsquedas. Las técnicas y los saberes pueden ser medios para encontrar formas de encontrar y no mensajes finitos y comprobables. El fin es la experimentación, la investigación, que involucre una observación participante trans-sensorial cuyo centro es la experiencia y no la memorización ni la repetición.

"Maestro es el que encierra una inteligencia en

4 En los laboratorios transdisciplinarios de la UArtes en Guayaquil realizados entre mayo y septiembre del 2015 por primera vez, nos planteamos desde un inicio que los estudiantes mantengan una bitácora a la que yo no exijo acceso al contenido pero sí a su existencia material y sus constantes cambios visibles, palpables, escuchables, etc. En el laboratorio planteamos una serie de actividades y experiencias planteadas por el profesor seguidas de experimentos en los que los estudiantes son obligados a pensar y plantear una actividad que nos involucre a todos en el laboratorio y que abra un camino de búsqueda o preguntas sobre una búsqueda concreta. el círculo arbitrario de dónde solo saldrá cuando se haga necesario para ella misma."(Ibid12) Ese precisamente es el trabajo del profesor de arte en general, y del profesor de investigación artística en particular: "comenzar el círculo de la emancipación de sus estudiantes"(Ibid:13), al utilizar el "poder" de ser el profesor según las jerarquías de la institución educativa, no para reproducir la modernidad sino para obligar a la voluntad, a la inteligencia de sus estudiantes a ponerse a trabajar. Imagino, junto a Ranciere, y Jacorot, el pedagogo que inspira a Ranciere, la posibilidad que, con buenos medios a disposición, biblioteca, media lab, materiales y maestros emancipados, esta pedagogía pueda ser usada en la trasmisión-generación de todo el conocimiento humano. Las artes siempre pueden ser una puerta a un campo transdiciplinario de diseño y construcción de experiencias y de relaciones y la educación artística emancipadora formará artistas que trabajen hacia la emancipación de sus pares desde y con el arte.

\section{Bibliografía}

Aguirre, I., 2004, Beyond the Understanding of Visual Culture:A Pragmatist Approach to Aesthetic Education, The International Journal of Art and Design Education,23.3.

Ascott, R., 2003. Telematic Embrace, Visionary Theories of Art, Techonology and Consciousness, University of California Press, Berkeley, USA.

Clifford, J., 1988, Dilemas de la Cultura, Gedisa Editorial, Barcelona.

Geertz, C., 1976, Art as a Cultural System, MLN, Vol.91, No.6, Comparative literature.

Kaprow, A., 1993, Essays on the Blurring of Art and Life. University of California Press, Berkeley, USA.

Muratorio, B., 2005.Historia de Vida de una Mujer Amazónica:intersección de autobiografía,etnografía e historia. En Iconos, No.22.Quito.(129-143)

Ranciere, J., 2003. El Maestro Ignorante:5 Lecciones 
sobre la Emancipación Intelectual. Laertes. Barcelona.

Wittgenstein, L., 1953 (1967) Philosophical

Investigations, Blackwell, Oxford.

1921 (2004) Tractatus Lógico-Filosófico, Alianza

Editorial, Madrid.

Wynne, J., 2010. Hearing Faces, Seeing Voices:Sound Art,Experimentalism and the Ethnographic Gaze, en Between Art and Anthropology, Contemporary Ethnographic Practice, Ed por Schneider,Arnd y Wright, Christopher. Berg. Oxford. 


\section{Normas de publicación:}

- Los escritos deberán ser originales e inéditos, presentados en su redacción denitiva.

- Los textos remitidos tendrán una extensión de entre 4 y 8 páginas.

- El texto debe estar redactado con fuente Times New Roman tamańo 12, interlineado 1,5 para el cuerpo del trabajo, las citas y la bibliografía y tamańo 10 para las notas al pie.

- Citación acorde a las normas APA. Por más información visite: http://normasapa.com/.

- En la primera página deberá constar la siguiente información:

1. Abstract del texto en 150 palabras.

2. 4 a 8 palabras claves que identiquen al texto

3. Biografía del autor/a máximo en 100 palabras. Debe incluir año y lugar de nacimiento, formación académica y otra información que considere relevante.

- En caso de incluir imágenes, estas deben tener un tamaño no menor de $30 \mathrm{~cm}$ en su lado más ancho y deben tener 300dpi de resolución. Los derechos de las imágenes deben estar liberados por sus respectivos autores y se debe incluir el crédito correspondiente según las normas APA.

- Los ensayos visuales deben incluir al menos 10 imágenes con un máximo de 15, deben además incluir un texto de al menos una página y un máximo de 4 con sujeción a las normas APA. Las imágenes deben tener un tamaño no menor de $30 \mathrm{~cm}$ en su lado más ancho y deben tener $300 \mathrm{dpi}$ de resolución.

- Los artículos se receptarán a través del correo electrónico: gmvargas@puce.edu.ec. En caso que sean textos con archivos de imagen se podrá enviar vía we transfer o dropbox.

Por más información puede contactarse con:

Gonzalo Vargas M.

Revista Índex Arte Contemporáneo

Carrera de Artes Visuales de la FADA, PUCE

gmvargas@puce.edu.ec

www.revistaindex.net 